Supporting Information

\title{
Early breeding failure in birds due to environmental toxins: a potentially powerful but hidden effect of contamination.
}

Jabi Zabala ${ }^{1}$, Joel C. Trexler ${ }^{2,3}$, Nilmini Jayasena ${ }^{4}$ and Peter Frederick ${ }^{1 *}$

1) Department of Wildlife Ecology and Conservation. University of Florida, Gainesville, Florida 32611. U.S.A.

2) Department of Biological Sciences, Florida International University, North Miami, Florida 33181, U.S.A.

3) Coastal \& Marine Laboratory, Florida State University, St. Teresa, Florida 32358, United States.

4) Department of Basic Veterinary Sciences. Faculty of Veterinary Medicine and Animal Science. University of Peradeniya. Peradeniya 20400. Sri Lanka.

* Corresponding author: P. Frederick, Department of Wildlife Ecology and Conservation.

P.O. Box 110430. University of Florida. Gainesville, Florida 32611-0430. E-mail:

pfred@ufl.edu

Supplementary details on methods for:

(1) Sampling fish biomass.

(2) Hg determination.

(3) Transformation of Great Egret nestling feather [Hg] into whole egg [Hg].

Supplementary results of the:

(4) Effect of experimental Hg exposure on probability of reaching the egg-laying stage.

Table S1: Results of model selection for each block of Great Egret models.

Table S2: Output of the best Great Egret model of each block. 
Table S3: Output of the best model for Great Egret using only colonies with exposure to $\mathrm{Hg}$ based on $>5$ nestling feathers.

Table S4: Comparison of breeding and life-history traits of Great Egret and White Ibis.

Figure S1: Deviation of individual Great Egret feather $[\mathrm{Hg}]$ values from their colony averaged values.

Figure S2: Correlation among predictive covariates in observational models.

Figure S3: Temporal pseudo-correlation in the residuals of the best model for Great Egret breeding number pairs.

Figure S4: Residuals of the best model for Great Egret numbers of breeding pairs.

\section{(1) Sampling of fish biomass}

We sampled small fish and macroinvertebrates using a $1-\mathrm{m}^{2}$ throw trap and standardized methods to remove all fish from the sampling device and provide an estimate of biomass ( $\mathrm{g} / \mathrm{m}^{2}$; Jordan et al., 1997). We selected this technique because its efficiency and possible biases for sampling fishes and macroinvertebrates in vegetated marshes have been evaluated in several calibration studies conducted in Everglades habitats. The method provides a relatively unbiased estimate of fish density and biomass over a range of sizes relevant for wading bird foraging $(>0.15 \mathrm{~cm}$ and $<8 \mathrm{~cm}$ standard length) and in the diversity of habitats sampled ${ }^{1,2}$. We determined PSUs using a Generalized Recursive Tessellation Sampling (GRTS) draw with post-stratification by landscape subunits ${ }^{3}$. Within each PSU identified by the randomization protocol, we collected three throw-trap samples in the wet season each year. We sampled approximately 150 PSUs per year between mid-September and early December. We collected fish-biomass data in these months because they encompass a period of relative hydrological and thermal stability that allowed sampling the whole study area under similar environmental conditions. This is also after most fish recruitment has ended and before winter temperatures affect aquatic communities, and just before the start of the annual water recession and the wading bird breeding season. 


\section{(2) Hg determination}

External contamination of feathers is a serious concern with some metals, yet for $\mathrm{Hg}$ it has found to be negligible ${ }^{4,5}$. Prior to analysis, we washed feathers with deionized water to remove non-feather materials from the surface and then oven dried them for 48 hours at $65^{\circ} \mathrm{C}$.

In the Chemistry Section of the Florida Department of Environmental Protection, whole feathers were digested with trace metal grade sulfuric acid and nitric acid, followed by 5\% potassium permanganate, and then analyzed for total Hg using a cold vapor atomic absorption spectrometer (Varian 30/40, Mulgrave, Australia; with deuterium background correction, fitted with cold vapor-hydride generator using stannous chloride reductant and automated with an SPS5 autosampler). A five-point calibration curve was created each day, and quality control samples for all runs included triplicate samples, digestion blanks of deionized water, high (4 $\mu \mathrm{g} / \mathrm{L})$ and low (1 $\mu \mathrm{g} / \mathrm{ml})$ methylmercury chloride sample matrix spikes, fish tissue standards (DORM-1 [National Research Council, Canada], 0.15-0.2 g), and a practical quantitation level standard inorganic Hg solution $(0.25 \mu \mathrm{g} / \mathrm{L})$.

When using the DMA (Direct Mercury Analyzer; DMA 80; Milestone inc.), in each analysis run of 20 - 40 samples we included at least two blanks, 4 samples of standard reference materials (DORM-2, DORM-4, DOLT-5 and TORT-21 [National Research Council, Canada]) and $15-25 \%$ of samples duplicates. All the duplicate concentrations were within $10 \%$ of the original sample (for further detail on methods see ${ }^{6-8}$ ). Recovery rates for reference materials in the 2014-2018 period were: $95.5 \%( \pm 1.9 ; N=12)$ for DORM-2, $101.6 \%( \pm 8.9 ; N=14)$ for DORM-4, 101.5\% $( \pm 1.7 ; N=31)$ for DOLT-2, 88.3\% $( \pm 3.8 ; N$ $=27$ ) for DOLT -5 , and 102.4\% $( \pm 6.2 ; N=19)$ for TORT-2. Analyses of Hg speciation in nestling feathers in an early phase of the study showed that virtually all $\mathrm{Hg}$ in nestling feathers (93-150\%) was MeHg ${ }^{9}$, a result that fits with other studies of feather Hg speciation ${ }^{10}$. We report results as total $\mathrm{Hg}$ (THg) on a dry weight (dw) basis and refer to all concentrations as [Hg], which we assume to represent [MeHg] in feathers. Average nestling feather [Hg] in Great Egret colonies in this study ranged between 2.24 and $19.34 \mathrm{THg} \mu \mathrm{g} / \mathrm{g} \mathrm{dw}$. We determined the average [Hg] in nestling feathers from the same colony and year using feather 
samples from an average of $8.94 \pm 3.78(4-26, N=52)$ individuals, each from different nests. Regarding nestling feathers of White Ibis from the experimental study, average nestling feather [Hg] was $0.319( \pm 0.068 ; N=18) \mu \mathrm{g} / \mathrm{g} \mathrm{dw} ; 1.676( \pm 0.270 ; N=13) \mu \mathrm{g} / \mathrm{g} \mathrm{dw} ; 3.711$ $( \pm 0.560 ; N=15) \mu \mathrm{g} / \mathrm{g} \mathrm{dw}$; and $8.867( \pm 0.903 ; N=11) \mu \mathrm{g} / \mathrm{g} \mathrm{dw}$ for control, low, intermediate and high-dose groups respectively. Regarding adult blood, average [Hg] was $0.078( \pm 0.015$; $N=11) ; 0.732( \pm 0.092 ; N=10) ; 1.599( \pm 0.319 ; N=10)$; and $3.946( \pm 0.678 ; N=10)$ for control, low, medium and high-dose groups respectively. As we had different sample sizes of White Ibis blood $(N=41)$ and nestling feathers $(N=57)$ and we could not always match parents with nestlings at feather collection (ibis nestlings are highly mobile after 14 days of age and often cannot be associated with a nest after that time) we used a bootstrap procedure to assess correlation between them. We randomly selected 10 adult blood [Hg] and 10 fledgling feather [Hg] values of each dose-group $(N=40)$ and ran a linear correlation. We repeated this step 10,000 times and calculated average parameter values from them.

\section{(3) Transformation of Great Egret nestling feather [Hg] into whole egg [Hg]}

To estimate equivalent whole egg [Hg] of averages great egret nestling feather [Hg] we used the following correlations: (1) from nestling feather [Hg] values to thin albumen [Hg] values correlation for Great Egret colony averages reported by Zabala et al. (2019b), forcing a 0-0 intercept (y =0.0215 x $\left.+0.0024 \mathrm{x}^{2} ; R^{2}=0.79\right)$; and (2) from thin albumen [Hg] to whole egg [Hg] estimates the correlation reported by Stebbins et al. $(2009 ; \log (y)=1.07$ $\left.\log (\mathrm{x})-0.41 ; R^{2}=0.94\right)$. Thus, the range of nestling feather [Hg] observed (2.24 to 19.34 $\mathrm{THg} \mu \mathrm{g} / \mathrm{g} \mathrm{dw}$ ) in Great Egrets are approximately equivalent to $0.06-1.31 \mathrm{THg} \mu \mathrm{g} / \mathrm{g}$ ww of thin albumen and $0.18-0.72 \mathrm{THg} \mu \mathrm{g} / \mathrm{g}$ ww whole egg. We caution that these transformations result in approximate values and they are only meant for comparison.

\section{(4) Effect of experimental $\mathrm{Hg}$ exposure on probability of reaching the egg-laying stage}

Model-predicted probability for a breeding attempt of unexposed White Ibis resulting in at least one egg was $0.96( \pm 0.04)$ compared to $0.82( \pm 0.13)$ for White Ibises exposed to MeHg. Pairs including at least one juvenile (individual in its second calendar year) breeder 
were also less likely to lay at least one egg $(\beta=-1.42 \pm 0.34$; $\mathrm{z}$ val $=-4.21 ; P<0.001, N=$ 449; $R^{2}$ part $=0.018$ [range 0.002-0.053]). Finally, number of breeding attempts per season was positively associated with egg-laying across dose-groups, and repeated attempts were more likely to result in chicks $\left(\beta=0.68 \pm 0.22 ; \mathrm{z} \mathrm{val}=3.09 ; P=0.002, N=449 ; R^{2}{ }_{\text {part }}=0.020\right.$ [range $0.002-0.053]$ ). In total, the model accounted for $15 \%$ of the observed variation in success of breeding attempts.

The linear model, the model assuming increases response at increases dose as opposed to the previous mode that compared control and dosed White Ibises regardless of dose, also detected a negative association with juvenile breeders $(\beta=-1.32 \pm 0.33$; $\mathrm{z}$ val $=$ -4.05; $P=0.0014, N=449 ; R^{2}$ part $=0.015$ [range 0.001-0.045]) and a positive association with number of previous attempts within the same breeding season $(\beta=0.66 \pm 0.22$; $\mathrm{z}$ val $=$ 2.99; $P=0.003, N=449 ; R^{2}$ part $=0.026$ [range 0.005-0.063]). All together the linear model of the effect of dose level explained $11 \%$ of the observed variation. 
Table S1: Results of model selection for models predicting numbers of breeding Great Egret pairs with maximum depth or fish biomass and year as random factor or with year as continuous covariate. We show the predictor covariates in each model considered and if we assessed them as additive $(+)$ or as full interaction $(*)$. We show the AIC $c$ of each model and the increment in AICc $(\triangle \mathrm{AIC} c$ ) with regards to the best model in the set, marked in bold. Na indicates that the model resulted in error.

\begin{tabular}{|c|c|c|}
\hline Model specification & AICc & $\triangle \mathrm{AICc}$ \\
\hline \multicolumn{3}{|c|}{ Max Depth and Year as random factor } \\
\hline 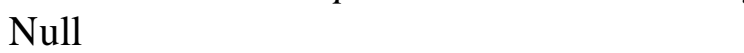 & 733.73 & 11.59 \\
\hline Full model & 726.68 & 4.53 \\
\hline Full + (Feather $[\mathrm{Hg}])^{2}$ & 729.61 & 7.47 \\
\hline Full with Max Depth * Rec. Range & 729.63 & 7.49 \\
\hline Full with Rec. Range * Feather $[\mathrm{Hg}]$ & 728.85 & 6.71 \\
\hline Full with Max Depth * Feather [Hg] & $\mathrm{Na}$ & $\mathrm{Na}$ \\
\hline Rec. Range + Max Depth + Feather [Hg] & 722.14 & 0 \\
\hline \multicolumn{3}{|c|}{ Max Depth and Year as covariate } \\
\hline 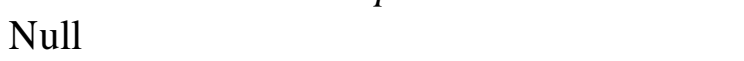 & 737.93 & 18.40 \\
\hline Full model & 726.55 & 7.02 \\
\hline Full $+(\text { Feather }[\mathrm{Hg}])^{2}$ & 729.49 & 9.95 \\
\hline Full with Max Depth * Rec. Range & 729.50 & 9.96 \\
\hline Full with Rec. Range * Feather $[\mathrm{Hg}]$ & 728.64 & 9.10 \\
\hline Full with Max Depth * Feather $[\mathrm{Hg}]$ & 731.13 & 11.59 \\
\hline Rec. Range + Max Depth + Feather [Hg] & 719.54 & 0 \\
\hline \multicolumn{3}{|c|}{ Fish Biomass and Year as random factor } \\
\hline Null & 733.73 & 9.14 \\
\hline Full model & 729.12 & 4.53 \\
\hline Full + (Feather $[\mathrm{Hg}])^{2}$ & 731.92 & 7.33 \\
\hline Full with Fish Biomass * Rec. Range & 729.03 & 4.44 \\
\hline Full with Rec. Range * Feather [Hg] & 731.39 & 6.80 \\
\hline Full with Fish Biomass * Feather $[\mathrm{Hg}]$ & 732.00 & 7.41 \\
\hline Rec. Range + Feather $[\mathrm{Hg}]$ & 724.59 & 0 \\
\hline \multicolumn{3}{|c|}{ Fish Biomass and Year as covariate } \\
\hline Null & 737.93 & 15.84 \\
\hline Full model & 728.40 & 6.31 \\
\hline Full + (Feather $[\mathrm{Hg}])^{2}$ & 731.15 & 9.06 \\
\hline Full with Max Depth * Rec. Range & 728.21 & 6.12 \\
\hline Full with Rec. Range * Feather $[\mathrm{Hg}]$ & 730.59 & 8.50 \\
\hline Full with Max Depth * Feather $[\mathrm{Hg}]$ & 731.25 & 9.16 \\
\hline Rec. Range + Feather $[\mathrm{Hg}]$ & 722.09 & $\mathbf{0}$ \\
\hline
\end{tabular}


Table S2: Output of the best model of Great Egret breeding pairs for each set of models showing, when appropriate, the variation (Var), the beta estimate (Est), the standard error (SE), the value of the $\mathrm{Z}$ statistic ( $\mathrm{z}$. Val), and the associated $p$ value of random and fixed factors retained in the best model. Rec. Range stands for recession range, the difference in water depth between the highest water level at the start of the year and the lowest water level recorded during the breeding season. Feather [Hg] indicated the average [Hg] in feathers of nestlings from the colony. We also indicate the marginal $\left(R^{2}\right.$ marg $)$ and conditional coefficient of determinations $\left(R^{2}\right.$ cond $)$.

\begin{tabular}{|c|c|c|c|c|c|c|c|c|}
\hline & & Varia & ble & & & & & \\
\hline & & Fixed & Random & Var. & Est & $\mathrm{SE}$ & z Val. & $p$ \\
\hline & $N=57$ & & Colony & 0.12 & & 0.35 & & \\
\hline & & & Year & 0 & & 0 & & \\
\hline & $\begin{array}{l}R^{2} \text { marg }=0 \\
70\end{array}$ & Intercept & & & 5.30 & 0.13 & 40.35 & $<0.001$ \\
\hline & $R_{\text {cond }}^{2}=0.99$ & Rec. Range & & & 0.31 & 0.09 & 3.47 & $<0.001$ \\
\hline & & Max. Depth & & & 0.32 & 0.12 & 2.74 & 0.006 \\
\hline Max Depth & & Feather $[\mathrm{Hg}]$ & & & -0.26 & 0.09 & -2.88 & 0.004 \\
\hline model set & $N=57$ & & Colony & 0.12 & & 0.35 & & \\
\hline & $R_{\text {marg }}^{2}=0.70$ & Intercept & & & 5.30 & 0.13 & 40.35 & $<0.001$ \\
\hline & $R^{2}$ cond $=0.99$ & Rec. Range & & & 0.31 & 0.09 & 3.47 & $<0.001$ \\
\hline & & Max. Depth & & & 0.32 & 0.12 & 2.74 & 0.006 \\
\hline & & Feather [Hg] & & & -0.26 & 0.09 & -2.88 & 0.004 \\
\hline & $N=57$ & & Colony & 0.31 & & 0.55 & & \\
\hline & & & Year & 0 & & 0 & & \\
\hline & $R^{2}$ marg $=0.41$ & Intercept & & & 5.19 & 0.17 & 30.83 & $<0.001$ \\
\hline & $R^{2}$ cond $=0.99$ & Rec. Range & & & 0.36 & 0.08 & 4.37 & $<0.001$ \\
\hline Fish Biomass & & Feather $[\mathrm{Hg}]$ & & & -0.28 & 0.09 & -2.98 & 0.003 \\
\hline Model set & $N=57$ & & Colony & 0.31 & & 0.55 & & \\
\hline & $R^{2}$ marg $=0.41$ & Intercept & & & 5.19 & 0.17 & 30.83 & $<0.001$ \\
\hline & $R^{2}$ cond $=0.99$ & Rec. Range & & & 0.36 & 0.08 & 4.37 & $<0.001$ \\
\hline & & Feather $[\mathrm{Hg}]$ & & & -0.28 & 0.09 & -2.98 & 0.003 \\
\hline
\end{tabular}


Table S3: Output of the best model for Great Egret breeding pairs considering only colonies for which we estimated average [Hg] using feathers from six or more different nests. We show, when appropriate, the variation (Var), the beta estimate (Est), the standard error (SE), the value of the $\mathrm{Z}$ statistic ( $\mathrm{z}$. Val), and the associated $p$ value of random and fixed factors retained in the best model. Rec. Range stands for recession range, the difference in water depth between the highest water level at the start of the year and the lowest water level recorded during the breeding season. Max Depth indicates the maximum water depth around the colony at the start of the breeding season. Feather [Hg] indicates the average [Hg] in feathers of nestlings from the colony. We also indicate the marginal $\left(R^{2}\right.$ marg $)$ and conditional coefficient of determinations $\left(R^{2}\right.$ cond $)$.

\begin{tabular}{|c|c|c|c|c|c|c|c|}
\hline & \multicolumn{2}{|c|}{ Variable } & \multirow{2}{*}{ Var. } & \multirow{2}{*}{ Est } & \multirow{2}{*}{ SE } & \multirow{2}{*}{ z Val. } & \multirow{2}{*}{$p$} \\
\hline & Fixed & Random & & & & & \\
\hline$N=47$ & & Colony & 0.08 & & 0.30 & & \\
\hline$R_{\text {marg }}^{2}=0.41$ & Intercept & & & 5.35 & 0.13 & 42.72 & $<0.001$ \\
\hline \multirow[t]{3}{*}{$R^{2}{ }_{\text {cond }}=0.99$} & Rec. Range & & & 0.23 & 0.10 & 2.17 & 0.030 \\
\hline & Max Depth & & & 0.38 & 0.12 & 3.19 & 0.001 \\
\hline & Feather [Hg] & & & -0.28 & 0.10 & -2.67 & 0.007 \\
\hline
\end{tabular}


Table S4: Comparison of ecology and life history traits of species studied. Data are generic for species throughout their distribution range but in some cases we included results from our study area (in italic font in the text). Adult body mass, length and wingspan are ranges. Lifespan shows the approximated lifespan for the species with the highest recorded I the wild in parenthesis. Clutch and Brood size show the average clutch and brood-size with their standard error of pairs breeding in the Everglades while in parenthesis we show ranges reported in literature. Main food details the staple foods of each species in the study area. Incubation length and nestling period the duration of each phase, note that the end of the nestling phase does not correspond with independence of offspring but with ages at which they are highly mobile and feathered, and can spend time out of nest. Information extracted from ${ }^{13-19}$.

\begin{tabular}{lcc}
\hline \multicolumn{1}{c}{ Trait } & Great Egret & White Ibis \\
\hline Adult Body Mass & $0.7-1.5 \mathrm{~kg}$ & $0.75-1.05 \mathrm{Kg}$ \\
Length & $94-104 \mathrm{~cm}$ & $55-68 \mathrm{~cm}$ \\
Wingspan & $131-145 \mathrm{~cm}$ & $90-105 \mathrm{~cm}$ \\
Lifespan & 15 years $(22)$ & 15 years $(16)$ \\
Age at first breeding & $2-3$ years & $2-3$ years \\
Clutch size & $2.62 \pm 0.65(1-6)$ & $2.44 \pm 0.67(1-5)$ \\
Brood size & $1.86 \pm 1.20(1-4)$ & $1.40 . \pm 1.12(0-4)$ \\
Main food & Fish & Crustaceans, fish \\
Incubation length & $23-27$ days & $18-21$ days \\
Nestling period & $21-25$ days & $14-17$ days \\
Foraging technique & Visual forager & Tactile forager \\
Habitat & Wetlands & Wetlands \\
Distribution & America, Africa, Europe & America \\
\end{tabular}


Figure S1: Deviation of individual feather [Hg] values from their colony averaged values. No right tail was observed and absolute values of observations below the average did not differ from these above (Gaussian GLMM with colony as random factor, $\mathrm{t}$ val $=1.12$; $d f=$ 236; $p=0.265 ; N=337)$.

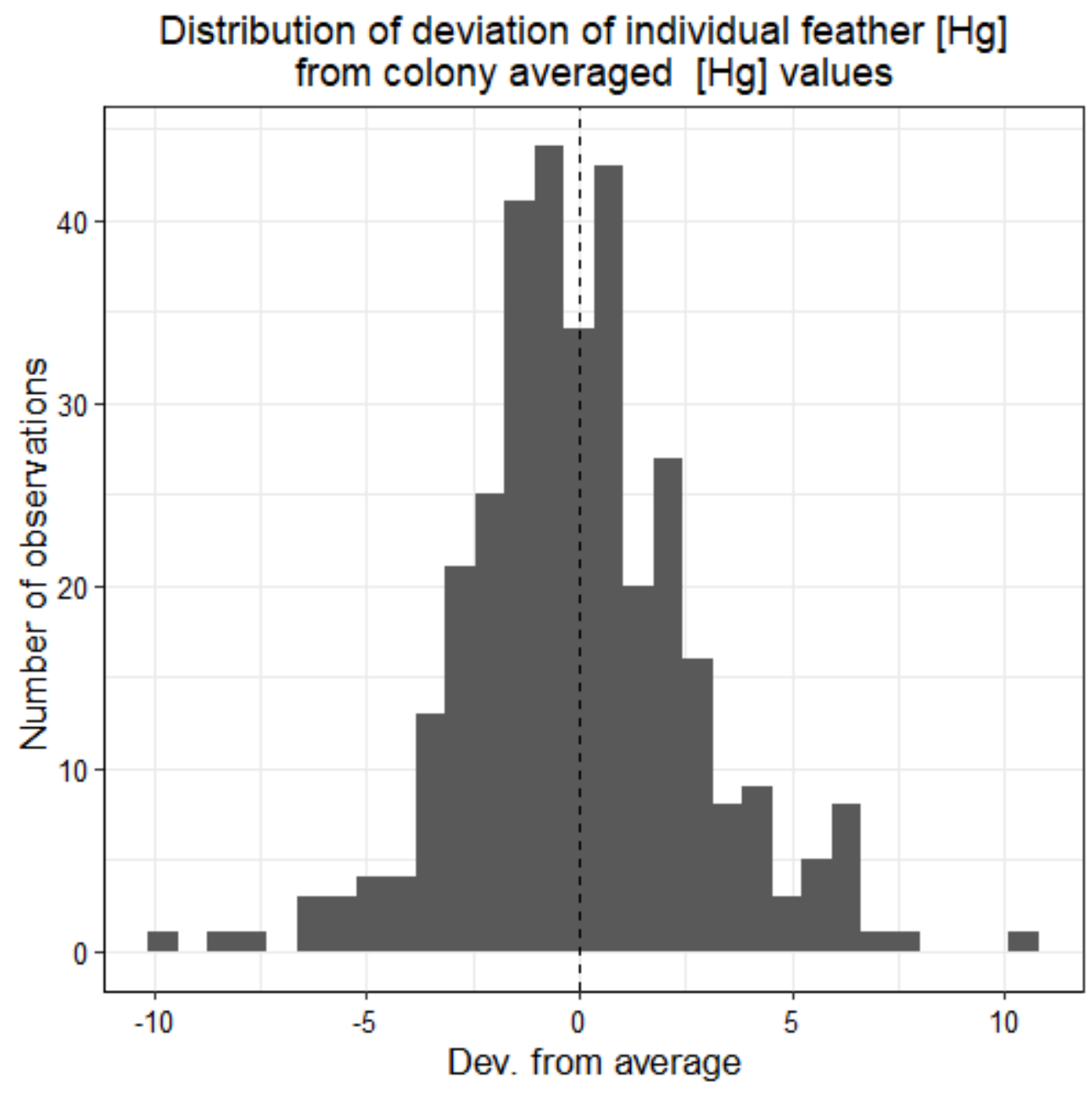


Figure S2: Correlation among predictive covariates. Avg. Fsh stands for average fish biomass, RsRng stands for recession range (difference between maximum and minimum depths), $\mathrm{Hg}$ indicates average [Hg] in nestling feathers collected from nestlings in the colony during that breeding season, Year is the year, Max is the average maximum depth around colonies at the start of the breeding season, HvyRain the number of days with $>0.95$ quantile of daily rain between January and May recorded at the gaging station closest to each colony, and Temp the average temperature in March when most Great Egrets are nesting. Numeric values indicate the Pearson correlation coefficient for each pair of covariates while circles show the same graphically: size of the circles indicate the strength of the correlation, blue circles indicate positive correlation while reddish ones indicate negative correlations. 


\begin{tabular}{|c|c|c|c|c|c|c|}
\hline Avg.Fsl & & & & & & \\
\hline 0.38 & RsRng & & & & & \\
\hline 0.09 & -0.03 & $\mathrm{Hg}$ & & & & \\
\hline-0.21 & 0.02 & 0.27 & Year & & & \\
\hline 0.64 & 0.33 & 0.2 & -0.09 & Max & & \\
\hline 0.06 & -0.49 & 0.03 & 0.07 & 0.02 & HvyRain & \\
\hline 0.04 & 0.04 & 0.09 & 0.21 & -0.33 & -0.1 & Temp \\
\hline
\end{tabular}


Figure S3: Temporal pseudo-correlation in the residuals of the best model. Lag indicates the number of years elapsed between observations. Blue dotted lines indicate values beyond which autocorrelations are significant.

\section{Temporal Auto-Correlation of Residuals}

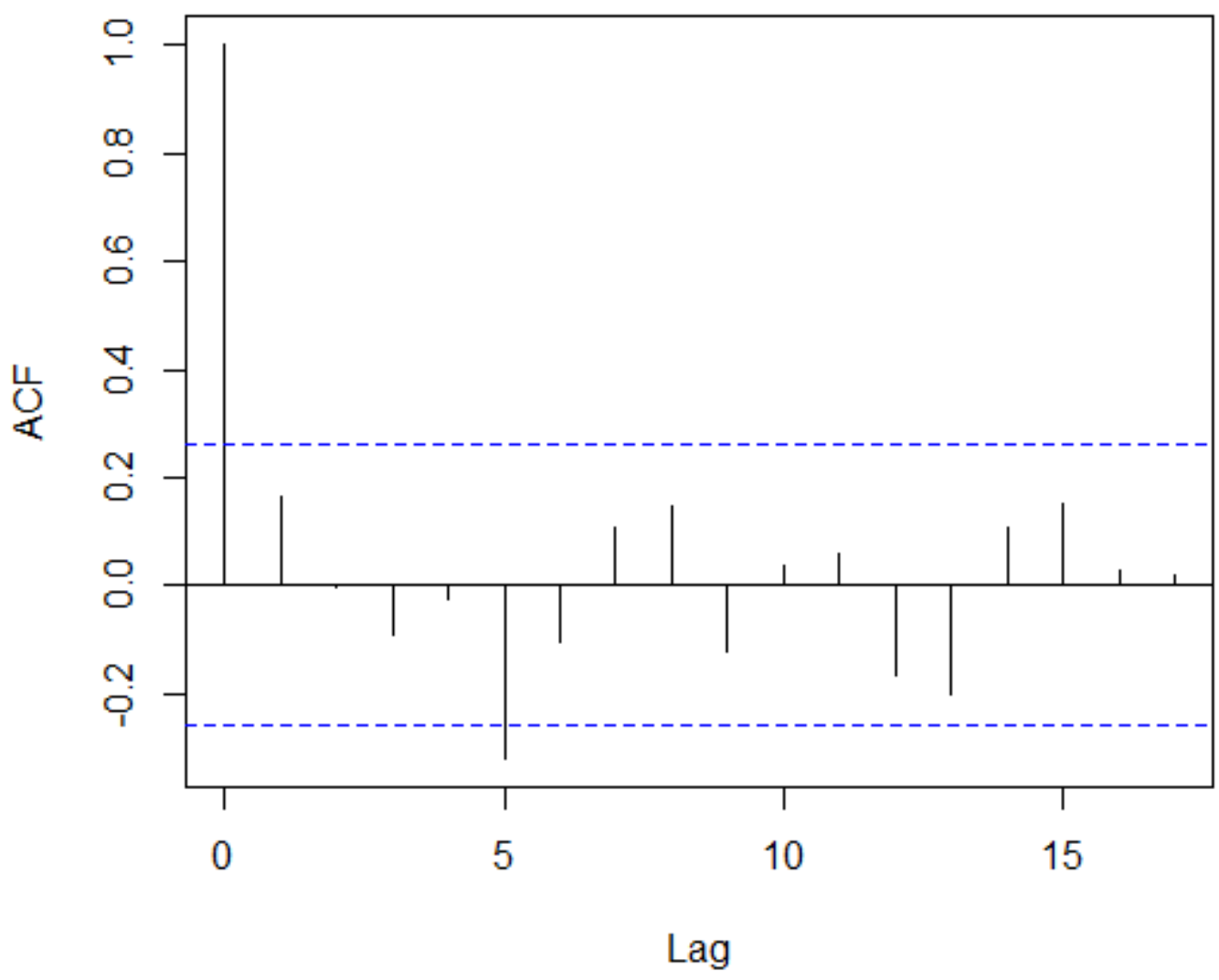


Figure S4: Residuals of the best model for associations between numbers of Great Egret breeding pairs in the colony and nestling feather $[\mathrm{Hg}]$ and recession range with colony as random factor (see Table 1).
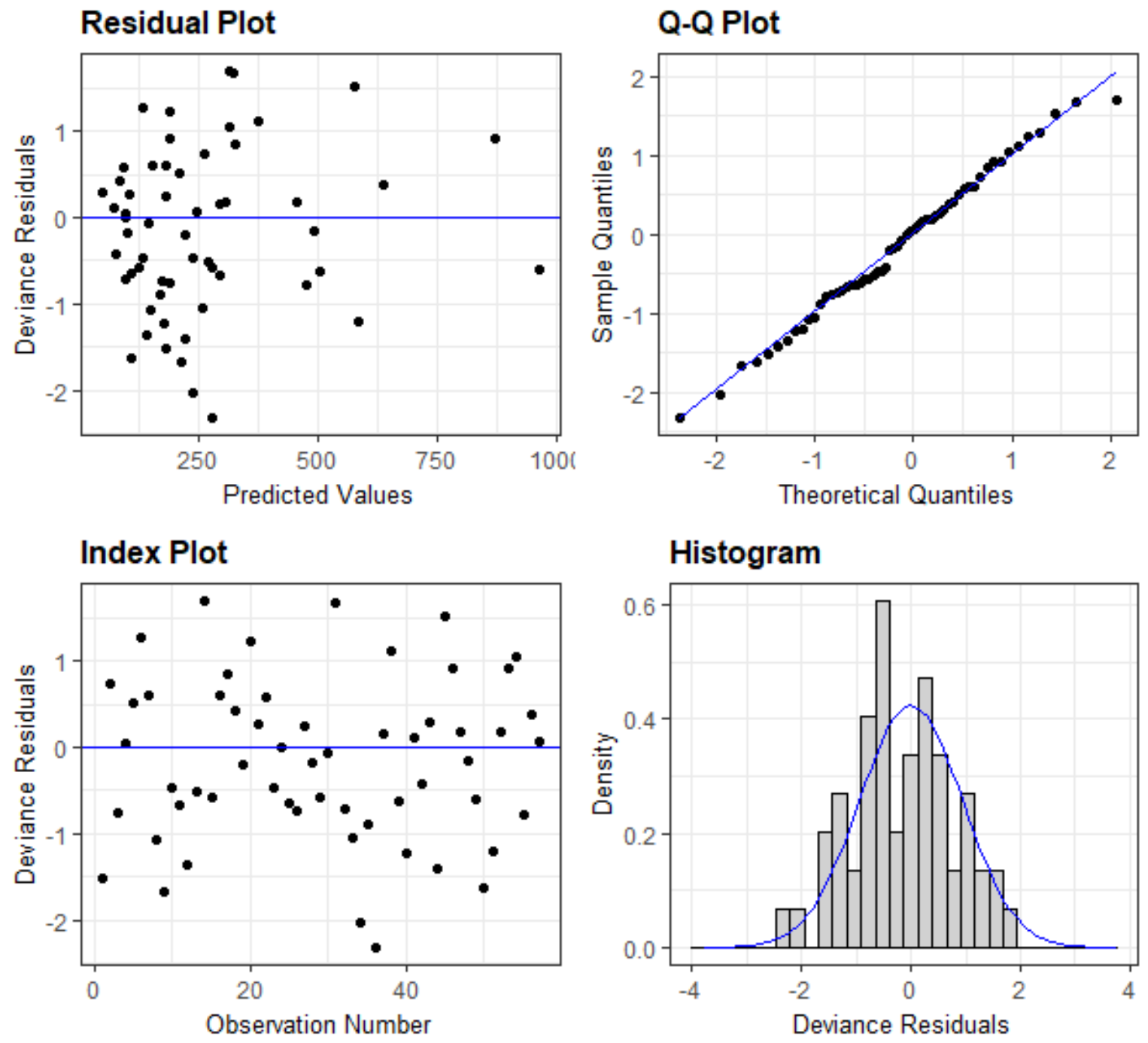
References

(1) Jordan, F.; Coyne, S.; Trexler, J. C. Sampling Fishes in Vegetated Habitats: Effects of Habitat Structure on Sampling Characteristics of the 1-m 2 Throw Trap. Trans. Am. Fish. Soc. 1997, 126 (6), 1012-1020. https://doi.org/10.1577/15488659(1997)126<1012:sfivhe>2.3.co;2.

(2) Gatto, J. V.; Trexler, J. C. Seasonality of Fish Recruitment in a Pulsed Floodplain Ecosystem: Estimation and Hydrological Controls. Environ. Biol. Fishes 2019, 102 (4), 595-613. https://doi.org/10.1007/s10641-019-00856-9.

(3) Stevens, D. L.; Olsen, A. R. Spatially Balanced Sampling of Natural Resources. J. Am. Stat. Assoc. 2004, 99 (465), 262-278. https://doi.org/10.1198/016214504000000250.

(4) Goede, A.; De Bruin, A. The Use of Bird Feathers for Indicating Heavy Metal Pollution. Environ. Monit. Assess. 1986, 7 (c), 85-98. https://doi.org/10.1007/97894-009-1467-4_11.

(5) Borghesi, F.; Dinelli, E.; Migani, F.; Béchet, A.; Rendón-Martos, M.; Amat, J. A.; Sommer, S.; Gillingham, M. A. F. Assessing Environmental Pollution in Birds: A New Methodological Approach for Interpreting Bioaccumulation of Trace Elements in Feather Shafts Using Geochemical Sediment Data. Methods Ecol. Evol. 2017, 8 (1), 96-108. https://doi.org/10.1111/2041-210X.12644.

(6) Frederick, P. C.; Spalding, M. G.; Dusek, R. Wading Birds as Bioindicators of Mercury Contamination in Florida, USA: Annual and Geographic Variation. Environ. Toxicol. Chem. 2002, 21 (1), 163-167. https://doi.org/10.1002/etc.5620210123.

(7) Zabala, J.; Meade, A. M.; Frederick, P. Variation in Nestling Feather Mercury Concentrations at Individual, Brood, and Breeding Colony Levels: Implications for Sampling Mercury in Birds. Sci. Total Environ. 2019, 671, 617-621. https://doi.org/10.1016/j.scitotenv.2019.03.382.

(8) Zabala, J.; Rodriguez-Jorquera, I. A.; Orzechowski, S. C.; Frederick, P. Mercury Concentration in Nestling Feathers Better Predicts Individual Reproductive Success than Egg or Nestling Blood in a Piscivorous Bird. Environ. Sci. Technol. 2019, 53 (3), 1150-1156. https://doi.org/10.1021/acs.est.8b05424.

(9) Spalding, M. G.; Frederick, P. C.; McGill, H. C.; Bouton, S. N.; McDowell, L. R. Methylmercury Accumulation in Tissues and Its Effects on Growth and Appetite in Captive Great Egrets. J. Wildl. Dis. 2000, 36 (3), 411-422.

https://doi.org/10.7589/0090-3558-36.3.411.

(10) Renedo, M.; Bustamante, P.; Tessier, E.; Pedrero, Z.; Cherel, Y.; Amouroux, D. Assessment of Mercury Speciation in Feathers Using Species-Specific Isotope Dilution Analysis. Talanta 2017, 174, 100-110. https://doi.org/10.1016/j.talanta.2017.05.081. 
(11) Zabala, J.; Rodriguez-Jorquera, I. A.; Orzechowski, S. C.; Frederick, P. Non-Lethal Sampling of Avian Indicators Reveals Reliable Geographic Signals of Mercury despite Highly Dynamic Patterns of Exposure in a Large Wetland. Environ. Pollut. 2019, 577-585. https://doi.org/10.1016/j.envpol.2019.01.057.

(12) Stebbins, K. R.; Klimstra, J. D.; Eagles-Smith, C. a; Ackerman, J. T.; Heinz, G. H. A Nonlethal Microsampling Technique to Monitor the Effects of Mercury on Wild Bird Eggs. Environ. Toxicol. Chem. 2009, 28 (3), 465-470. https://doi.org/10.1897/08-316.1.

(13) Heath, J. A.; Frederick, P. C.; Kushlan, J. A.; Bildstei, K. L. White Ibis https://birdsna.org/Species-Account/bna/species/whiibi/introduction (accessed Dec 11, 2019).

(14) McCrimmon Jr., D.A Ogden, J. C.; Bancroft, G. T.; Martínez-Vilalta, A.; Motis, A.; Kirwan, G. M.; Boesman, P. F. D. Great Egret (Ardea Alba). In Birds of the World; Billerman, S. M., Ed.; Cornell Lab of Ornithology: Ithaca, New York, 2020.

(15) Beerens, J. M.; Gawlik, D. E.; Herring, G.; Cook, M. I. Dynamic Habitat Selection by Two Wading Bird Species with Divergent Foraging Strategies in a Seasonally Fluctuating Wetland With Divergent Foraging in a Seasonally Fluctuatuing Wetland. 2011, 128 (4), 651-662.

(16) Frederick, P. C.; Bildstein, K. L.; Fleury, B.; Ogden, J. Conservation of Large , Nomadic Populations of White Ibises ( Eudocimus Albus ) in the United States. Conserv. Biol. 1996, 10 (1), 203-216.

(17) Frederick, P. C.; Collopy, M. W. Nesting Success of Five Ciconiiform Species in Relation to Water Conditions in the Florida Everglades. Auk 1989, 106 (4), 625-634.

(18) Frederick, P. C.; Spalding, M. G.; Sepulveda, M. S.; Williams, G. E.; Nico, L.; Robins, R. Exposure of Great Egret (Ardea Albus) Nestlings to Mercury through Diet in the Everglades Ecosystem. Environ. Toxicol. Chem. 1999, 18 (9), 19401947.

(19) Boyle, R. A.; Dorn, N. J.; Cook, M. I. Nestling Diet of Three Sympatrically Nesting Wading Bird Species in the Florida Everglades. Waterbirds 2012, 35 (1), 154-159. https://doi.org/10.1675/063.035.0116. 